\title{
O PROFESSOR PRIMÁRIO NO INÍCIO DO SÉCULO XX: UM ESTUDO SOBRE AS CARACTERÍSTICAS PROFISSIONAIS PARA A InstruÇão PÚblica Mato-Grossense em 1908
}

\author{
THE PRIMARY TEACHER AT THE BEGINNING OF THE 2OTH CENTURY: A \\ STUDY ON PROFESSIONAL CHARACTERISTICS FOR PUBLIC INSTRUCTION \\ IN MATO GROSSO IN 1908
}

DOI: 10.23926/RPD.2526-2149.2020.v5.n3.p2033-2050.id900

\section{Mariana Gomes de Oliveira \\ Mestra em Ensino (UNIC) marianagoliveira12@gmail.c \\ $\underline{\mathrm{om}}$}

\section{Laura Isabel Marques Vasconcelos de}

Almeida

Doutora em Educação (PUCPR)

Docente do Programa de Pós-Graduação em Ensino da Universidade de Cuiabá (UNIC)

lauraisabelvasc@hotmail.co $\underline{m}$

\section{Wagner Rodrigues \\ Valente}

Doutor em Educação (USP)

Docente do Programa de Pós Graduação da Universidade Federal de São Paulo (UNIFESP) e Presidente do GHEMAT Brasil. Wagner.valente@unifesp.br
Resumo: Este artigo é parte do resultado da pesquisa de Mestrado em Ensino da Universidade de Cuiabá/MT. Tem como objetivo apresentar as características profissionais esperadas pela Administração Pública quando do ingresso dos professores no ensino primário mato-grossense. Embasado na dimensão metodológica histórico-cultural, a pesquisa vincula-se ao grupo Ghemat Brasil e pauta-se nas contribuições metodológica de autores como, De Certeau (1982), Chervel (1990), França (2016), Julia (2001), Leite (1970) e Valente (2006). O percurso teórico-metodológico constitui-se por meio da narrativa acerca da construção do perfil profissional docente no período da Primeira República no Estado de Mato Grosso, a partir de fontes inventariadas no Instituto Memória e Arquivo Público produzidos nos anos finais do século XIX e início do século XX. O estudo aponta os elementos essenciais para compreensão da construção histórica dos Regulamentos que determinavam os preceitos para a Instrução Pública Primária do Estado de Mato Grosso e as fontes revelam os processos e dinâmicas que regulamentavam a profissão docente do período.

Palavras-chave: Professor Primário. Instrução Pública Matogrossense. Cultura Escolar.

\begin{abstract}
This article is part of the result of the Master's in Education research at the University of Cuiabá / MT. It aims to present the professional characteristics expected by the Public Administration when teachers enter primary education in Mato Grosso. Based on the historical-cultural methodological dimension, the research is linked to the Ghemat Brasil group and is based on the methodological contributions of authors such as De Certeau (1982), Chervel (1990), France (2016), Julia (2001), Leite (1970) and Valente (2006). The theoretical-methodological path is constituted through the narrative about the construction of the professional teaching profile in the period of the First Republic in the State of Mato Grosso, from sources inventoried in the Memory and Public Archive Institute produced in the late nineteenth and early years of the 20th century. The study points out the essential elements for understanding the historical construction of the Regulations that determined the precepts for the Primary Public Instruction of the State of Mato Grosso and the sources reveal the processes and dynamics that regulated the teaching profession of the period.
\end{abstract}

Keywords: Primary Teacher. Public Instruction in Mato Grosso. School Culture. 


\section{INTRODUÇÃO}

Este artigo apresenta parte do resultado da Pesquisa de Mestrado do Programa de PósGraduação da Universidade de Cuiabá em associação com o Instituto Federal de Mato Grosso, com o objetivo de analisar o perfil profissional do professor primário descrito nos documentos oficiais do período compreendido nos primeiros anos de escolarização do século XX do Estado de Mato Grosso.

O estudo se desenvolveu a partir dos aspectos históricos e culturais da escola elementar da Primeira República no Estado de Mato Grosso, que passou de Província, subjugada ao poder hierárquico da Coroa Portuguesa, para Estado com autonomia administrativa e possibilidades de regulamentar seus próprios interesses, dentre eles, a Instrução Pública Primária.

Realizamos considerações iniciais acerca de conceitos básicos sobre a construção da história da educação e da necessidade de analisar os documentos oficiais como produções históricas de tempos de outrora, que por certo nos revelam parcialmente como era vislumbrada e exigida o perfil profissional esperado do professor primário do período no discussão.

Neste estudo, realizamos apontamentos na tentativa de responder os seguintes questionamentos: Quem era o professor do início do século XX no Estado de Mato Grosso? Quais as exigências para ingresso na carreira docente na instrução primária? Com o objetivo de respondê-las destacamos os documentos oficiais que regulamentavam o ingresso de candidatos aos cargos da Instrução Primária previstos no edital publicado no ano de 1909, bem como, os demais documentos inventariados no acervo disponível no Arquivo Público do Estado de Mato Grosso.

\section{ASPECTOS TEÓRICOS E METODOLÓGICOS DA PESQUISA}

Além das produções acadêmicas e literatura específica sobre a história da educação mato-grossense, nos valemos dos acervos históricos constituídos de fontes preciosas da época, especialmente nos acervos públicos que podem ser consultados por qualquer pesquisador.

Para conferir legitimidade aos resultados obtidos, a pesquisa foi realizada a partir da dimensão metodológica ancorada na abordagem histórico-cultural que se fundamentou nos aportes teóricos e metodológicos de historiadores locais e autores renomados da história e do ensino: De Certeau (1982), Chervel (1990), França (2016), Julia (2001), Leite (1970) e Valente (2006) que contribuem para a construção da narrativa do presente artigo e fortalece a utilização da metodologia empregada, qual seja, a metodologia histórico-cultural com base nas análises 
de fontes documentais, com abordagem qualitativa para delimitar o período de estudo e obtenção de resposta ao objetivo proposto.

Os historiadores, em especial, Julia (2001) e Chervel (1990), contribuem de forma peculiar por meio da narrativa que se constitui como metodologia para a compreensão do período escolar ocorrido há mais de um século e discutem o modo de fazer pesquisa com o ferramental indispensável para a escrita da historiografia da educação brasileira.

Julia (2001) esclarece que no estudo sobre a cultura escolar de outros tempos, devemse considerar os resquícios documentais existentes, a produção do período, como as leis, os cadernos, livros, dentre outros elementos disponíveis e acessíveis nos arquivos escolares. O autor ainda destaca que a reconstrução da história das práticas culturais é uma das tarefas mais difíceis de realizar, por se tratar de um ambiente escolar e que, como tal, deveria por certo ter um número considerável de documentos escritos disponíveis para pesquisa e reconstrução dos traços culturais. Os documentos escolares, conforme os apontamentos de Julia (2001), geralmente são descartados ou poucos conservados, evidenciando assim as dificuldades do ofício de historiador e da utilização da metodologia histórico-cultural. No entanto, o estudioso destaca que na ausência das fontes, cabe ao historiador fazer "flechas com qualquer graveto" (2001, p.17).

As fontes documentais que endossam a adoção da metodologia histórico-cultural para a construção do enredo se constituem a partir dos Regulamentos da Instrução Primária, mensagens presidenciais, resoluções, documentos de inscrição no concurso para provimento no cargo docente (atestado de idoneidade e autorização do responsável legal), exames, dentre outros que contribuíram para as conclusões do trabalho, com ênfase no período histórico em debate.

Nossa proposta foi reconstituir o ingresso do professor na Instrução Pública Primária do Estado de Mato Grosso, ciente do desafio, almejamos ao final compreender quais eram as características profissionais exigidas para o exercício da docência nas escolas públicas matogrossenses.

\section{A Cultura Escolar: o Professor primário do século XX nO estado de Mato Grosso}

Visando constituir e elaborar uma narrativa aproximada do período escolar, os estudos de Almeida (2010) destacam que para compreender as representações do passado, se faz necessário o acesso aos documentos institucionalizados, sendo compreendidos os Regimentos 
editados pelos governantes à época, exames, atas, dentre outros elementos que foram primordiais para melhor compreensão da cultura escolar de outros tempos.

Nessa perspectiva, Julia (2001) nos ensina a analisar a escola de dentro para fora, buscando compreender o verdadeiro funcionamento da instituição com a finalidade de evitar a ilusão de um poderio totalitário da escola. Entender a cultura escolar, segundo Julia (2001) não é realizar somente uma análise "externalista", mas também, acessar a história das ideias pedagógicas, com o objetivo de compreender cada um dos elementos da cultura escolar. $\mathrm{O}$ autor declara que:

\begin{abstract}
A história das instituições educativas não difere fundamentalmente das outras histórias das instituições (quer se trate de instituições militares, judiciais etc.). A história das populações escolares, que emprestou métodos e conceitos da sociologia, interessou-se mais pelos mecanismos de seleção e exclusão social praticados na escola que pelos trabalhos escolares, a partir dos quais se estabeleceu a discriminação (JULIA, 2001, p. 12).
\end{abstract}

Assim, cabe ao historiador analisar a "caixa preta" da escola para compreender o que ocorreu ou ocorre nos espaços escolares e ir além do documento, conhecendo a cultura própria de cada instituição, caracterizada por suas singularidades e apropriações.

Partindo dessa premissa, elegemos o seguinte questionamento: Que elementos são necessários para analisar a cultura escolar do período da Primeira República no Estado de Mato Grosso? Compreende-se muitas vezes que a história das práticas culturais se constitui em matéria difícil de reconstrução, conforme afirma Julia (2001) porque ela não deixa traços. Até que ponto os documentos realmente deixam vestígios da cultura escolar? Questões que nos permitem compreender que a cultura desenvolvida dentro espaço escolar, que vai além dos documentos escritos e produzidos por ela.

Julia (2001) ainda destaca que na grande maioria dos casos, os registros escolares são poucos conservados, o descrédito que se atribui a este gênero de produção, que periodicamente se acham os estabelecimentos escolares na obrigação de ganhar espaço, levou-nos a jogar no lixo 99\% das produções escolares (CHERVEL, 1988 apud JULIA, 2001).

De Certeau (1982) destacado nos estudos de Almeida (2010), afirma que para percorrermos o caminho até aqui trilhado é necessário conhecer de perto cada disciplina escolar. Outro fator preponderante é analisar suas implicações na cultura escolar, que segundo o autor, exige um grande esforço para entender a arte de fazer ou a maneira de fazer dos usuários que, como "caçadores", “jogadores", “fabricantes”, inventam ou reinventam mil maneiras de fazer seu próprio caminho, de forma bem peculiar. 
No entanto, analisamos o perfil profissional do professor que atuava nos espaços escolares nos primeiros anos de escolarização da Primeira República no Estado de Mato Grosso. Por questão de temporalidade limitada e com fulcro nas fontes inventariadas, destacamos o exame aplicado no concurso público para Provimento efetivo do cargo de professor do ano de 1909. Para tanto, nos valemos das fontes inventariadas junto ao Instituto Memória da Assembleia Legislativa do Estado de Mato Grosso, com destaque para o Regulamento da Instrução Pública Primária, editado no ano de 1896 que apresenta o Título II, suas respectivas seções, todos os ditames acerca da admissão, exercício e exoneração do professor.

O primeiro capítulo da Seção Primeira do Regulamento de 1896 sinaliza como primeiro ato de regulamentação do exercício da profissão docente, o artigo 200 apresentando as disposições acerca do provimento e supressão (extinção) das cadeiras do ensino primário, observando a preferência do legislador em regulamentar inicialmente, o ensino primário.

Tem-se como primeira exigência para o Provimento efetivo das cadeiras referente à carreira docente, a aprovação prévia em Concurso público a ser organizado e promovido pela Diretoria geral da Instrução Pública nomeada para tanto. Os exames deveriam ser realizados no mês de dezembro de cada ano, cabendo ao Diretor geral promover a realização do Concurso público no prazo máximo de noventa dias para preenchimento das cadeiras vagas. Abaixo, destacamos os requisitos exigidos para realizar a inscrição no concurso anunciado pelo Diretor geral:

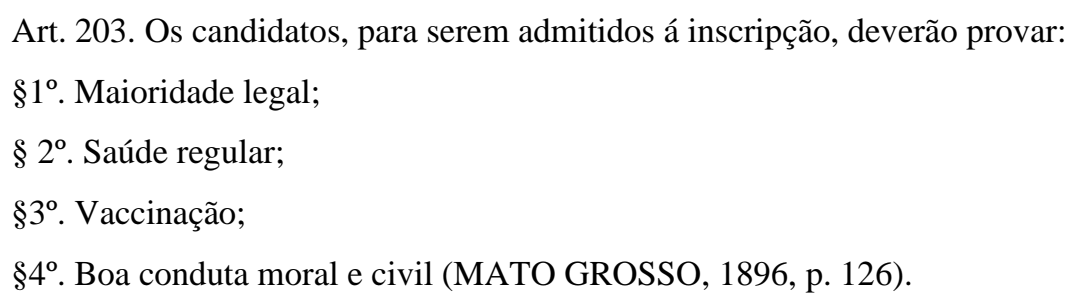

Devemos considerar que a época do Regulamento de 1896, a menoridade legal para fins penais era a partir de 9 anos de idade no caso de ocorrência de crimes, caso em que as crianças deveriam ser responsabilizadas da mesma forma como os adultos quando cometiam delitos e infrações ${ }^{1}$. Por sua vez, o Regulamento da Escola Normal, editado no ano de 1914, apresentava no artigo 32, a exigência de idade mínima de 14 anos para as mulheres e 15 anos para os

\footnotetext{
${ }^{1}$ Pelo Código Penal de 1890, criado após a queda do Império, crianças podiam ser levadas aos tribunais a partir dos 9 anos. Somente em 12 de outubro de 1927, no palácio do Catete, o presidente Washington Luiz assinava uma lei que ficaria conhecida como Código de Menores onde estabeleceu que o jovem é penalmente inimputável até os 17 anos e que somente a partir dos 18 responde por seus crimes e poder ser condenado à prisão. O Estatuto da Criança e do Adolescente (ECA) - uma espécie de filhote do Código de Menores que nasceu em 1990 estabelece a menoridade em idade de 18 anos completos (BRASIL, 2015).
} 
homens, para os fins de inscrição na Escola Normal, salvo se já provido da cadeira da instrução primária, sendo assim, excepcionada a exigência da idade mínima.

Os requisitos do artigo 203 do Regulamento seriam comprovados mediante a entrega dos seguintes documentos: certidão de idade, ou qualquer documento idôneo que suprisse a demonstração efetiva da maioridade legal; atestado médico de comprovação de saúde regular e vacinação, e por fim, o documento escrito e subscrito por terceiros, público ou particular, que comprovasse a conduta moral e civil do candidato à carreira pública de magistério.

Nas fontes localizadas no Arquivo Público do Estado de Mato Grosso fica evidenciado o cumprimento dessa exigência pela candidata Esmeraldina da Silva Paes no Concurso público realizado em 1908 para provimento efetivo das cadeiras do magistério, conforme demonstra a Figura 1.

Figura 1 - Atestado de Idoneidade, 1909

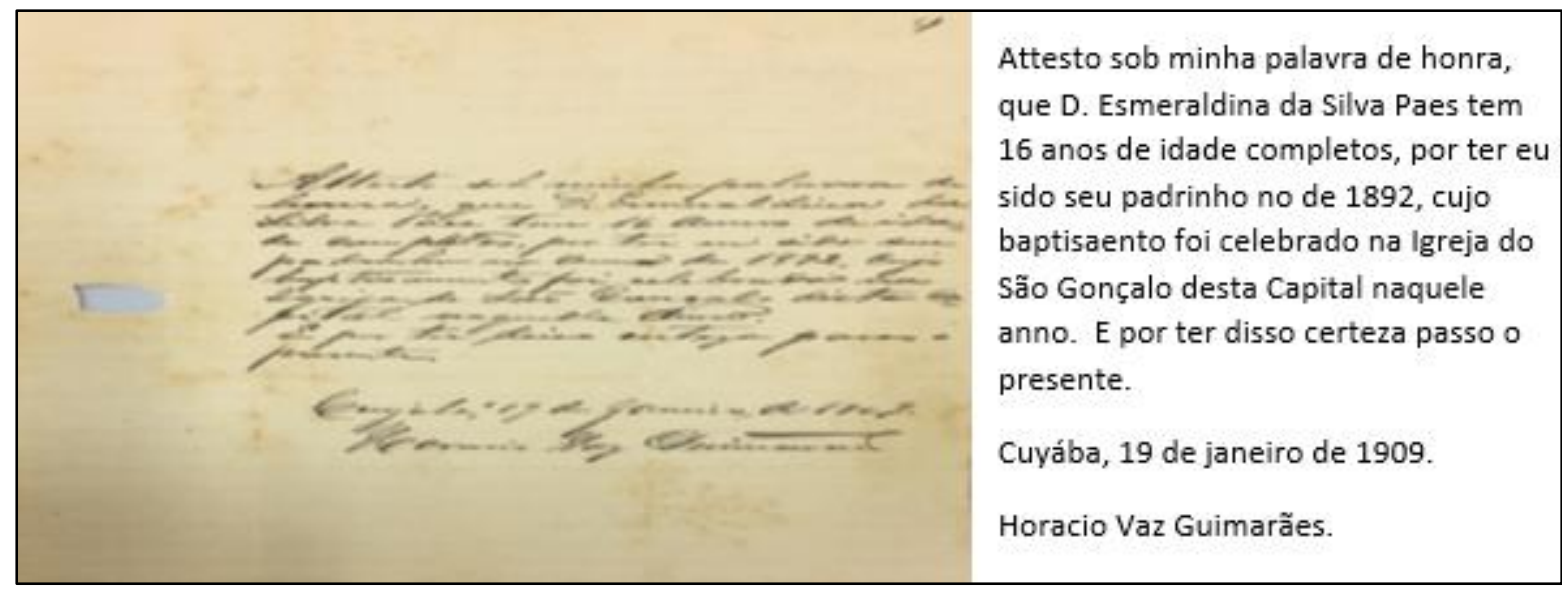

Fonte: Arquivo Público do Estado de Mato Grosso.

O documento revela o atendimento de uma das exigências do Artigo 206, em especial para as candidatas mulheres que fossem se inscrever no concurso público. Ou seja, o Regulamento apresenta que, se a candidata fosse solteira, deveria apresentar documento idôneo de autorização emitida pelo pai; se fosse órfã, autorização do tutor; se casada, autorização emitida pelo marido; se fossem viúvas, deveriam apresentar a certidão de óbito do marido; as divorciadas, a certidão da sentença de separação conjugal, devidamente transitada em julgado.

Os documentos inventariados no Arquivo Público do Estado de Mato Grosso demonstram o cumprimento de referida prescrição oficial, quando a candidata Sra. Esmeraldina da Silva Paes, mulher e solteira, juntou no ato do requerimento de inscrição declaração subscrita pelo seu genitor, demonstrado na Figura 2. 
Figura 2 - Consentimento do genitor da candidata, 1909

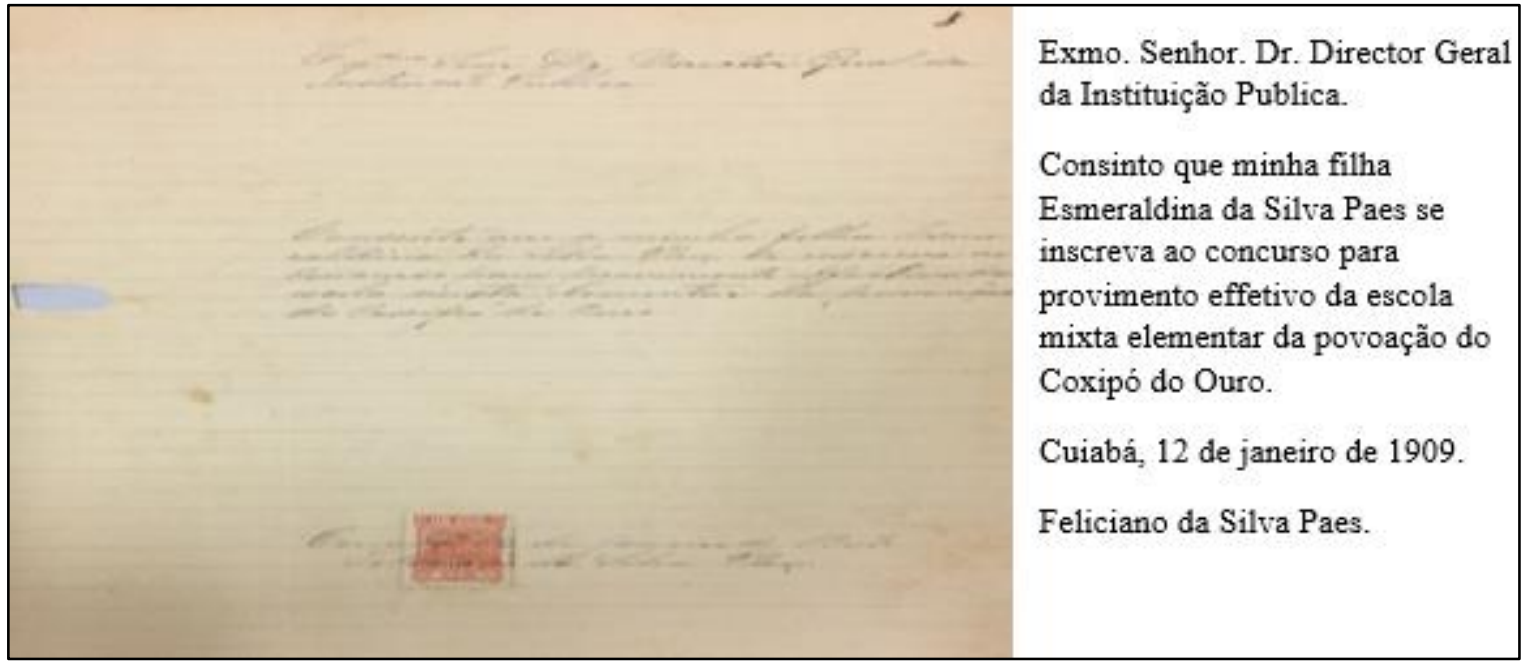

Fonte: Arquivo Público do Estado de Mato Grosso.

A figura 2 destaca que em relação às mulheres, a obrigatoriedade de instruir com documentos tidos por "autorização" ou "consentimento" se fazia necessário em decorrência de que a mulher era considerada relativamente incapaz, necessitando da documentação necessária para suprir a incapacidade imposta pela lei.

Adiante, o Regulamento de 1896 ainda apresentava rol taxativo acerca das pessoas que não poderiam se candidatar ao magistério e, conforme previsão do Artigo 208, não poderiam se inscrever no concurso os condenados por crime "deprimente”, sendo referida consideração dentro da esfera da administração pública, os que perderam o cargo de professor em decorrência de processo disciplinar; aqueles que foram condenados por crimes contra a moral e os bons costumes, e ainda, os acometidos de "defeitos físicos" ou doença que impossibilitava o exercício da docência. Verifica-se a hipótese de exclusão dos deficientes físicos e ainda, aqueles que por algum motivo, eram portadores de alguma doença (note-se que o Regulamento é subjetivo neste ponto, trazendo apenas a previsão genérica de incapacidade para o exercício do magistério).

Sobre a qualificação do candidato ao cargo de magistério, o Regulamento de 1896 (que igualmente regulamentou o edital de concurso público editado em 04 de dezembro de 1908), não apresentava com clareza o grau de instrução mínimo do candidato, sendo que o candidato ao exercício da docência deveria pelo menos ter frequentado a escola elementar.

O Artigo 218 do Regulamento destaca a seguinte orientação:

Art. 218. Se, annunciado um concurso, increver-se para elle um só candidato, será este examinado em um só dia; e, se o pretendente for normalista ou humanista, será effectivamente nomeado independente de exame (MATO GROSSO, 1896, p. 126). 
Neste caso, o candidato que não tivesse frequentado a Escola Normal (que, ressalta-se, neste período ainda estava no seu início e atendia um público muito pequeno), deveria ser submetido ao concurso, onde iriam ser exigidos os pontos sorteados no dia do exame, referente ao Programa do ensino elementar ou do ensino complementar, sendo que este último era destinado somente aos candidatos que estavam na disputa pelo exercício da docência na escola complementar.

O professor da Primeira República, embora fosse efetivado mediante a realização de concurso público, atravessava diversas exigências administrativas, o que demonstrava certa precariedade de pessoal administrativo nas escolas, bem como, o retrato da temporalidade da pesquisa. Dentre as exigências, consta que o professor uma vez nomeado para o exercício do professorado primário efetivo ou vitalício, tinha a obrigação de manter a frequência escolar, no mínimo de vinte alunos regulares.

O artigo 221 do Regulamento dispunha que, caso durante o período de seis meses consecutivos, a escola fosse frequentada por um público estudantil inferior a vinte alunos, o professor sofreria sanção administrativa:

Art. 221. O professor primário effectivo ou vitalício, cuja escola fôr frequentada, durante seiz meses consecutivos, por menos de vinte alumnos, perceberá somente metade dos vencimentos do logar, salvo se provar concludentemente que o facto se dá por motivo independente de sua vontade (MATO GROSSO, 1896, p. 129).

Fica evidenciado que a administração pública por meio do Regulamento, estabelecia um padrão de conduta aos professores. Caso um aluno viesse a "desistir" de frequentar a escola, a primeira hipótese que se levantava era a ineficiência ou descaso do professor primário, atribuindo a ele toda e qualquer reponsabilidade. Nesses termos, o professor deveria se esforçar para, além tornar o ensino prático e acessível, deveria ainda despertar o interesse nos alunos.

Vale lembrar que neste período, os professores sofriam inúmeras dificuldades e a grande maioria não dispunha de capacitação necessária para o bom desempenho da função docente na sala de aula. Além de ensinar com maestria e manter a frequência regular dos alunos, o Regulamento (1896) ainda dispunha que, caso a escola fosse frequentada por um número inferior de 10 alunos, seriam encerradas temporariamente as suas atividades e o professor não receberia nenhuma remuneração.

No entanto, se fosse constatado por meio de provas e indícios que o fechamento da escola em decorrência de pouca frequência dos alunos se deu por responsabilidade do professor, caso o docente contasse com mais de dois anos efetivos no exercício de magistério, a Administração Pública tinha a obrigação legal de aproveitá-lo em outra função administrativa 
até que fosse reintegrado em outra escola no exercício de sua função docente (artigo 224 do Regulamento de 1896).

Observa-se ainda que, caso houvesse necessidade de substituição temporária ou definitiva do professor da escola primária (exemplo: casos de moléstia), poderia exercer em seu lugar, em última hipótese, qualquer pessoa idônea e de reconhecida capacidade para o exercício do magistério. Em outras palavras, pessoas sem prévia qualificação poderiam exercer a função docente, reforçando assim, o tão propalado descrédito no ensino primário pela sociedade da época.

Acerca da estabilidade do professor primário, o Regulamento dispõe de três requisitos essenciais para que a Administração Pública reconhecesse a vitaliciedade do exercício da docência pública: ter sido nomeado mediante realização de concurso público; possuir cinco anos de exercício contínuo do magistério e por fim, ter aprovado no mesmo período de tempo, o total de quarenta alunos em exame. Neste caso, abria-se exceção à exigência de realização de concurso público aos professores que previamente tivessem obtido diploma do curso Humanista ou tivessem concluído o curso Normal.

Por sua vez, o exercício do magistério era incompatível com o exercício da advocacia e o professor não poderia cumular o exercício do professorado no secundário, ou qualquer outra profissão que impedisse o regular cumprimento dos seus deveres acadêmicos. Os professores primários dos primeiros anos de escolarização da Primeira República no Estado de Mato Grosso ainda deveriam obrigatoriamente se atentar aos seguintes deveres:

$\S 1^{\circ}$. Comparecer pontualmente á escola decentemente trajado, e proceder aos trabalhos escolares nos termos do respectivo regimento;

$\S 2^{\circ}$. Manter a ordem, disciplina e regularidade no ensino escolar;

$\S 3^{\circ}$. Inspirar a seus discípulos o amor e applicação ao estudo, e imprimir-lhes no anno, mais pelo exemplo do que pela palavra, o amor ao bem e o horror ao mal;

$\S 6^{\circ}$. Fazer todas as requisições que julgar convenientes, no sentido de melhorar a escola a seu cargo;

$\S 8^{\circ}$. Zelar do material da escola a seu cargo, sendo responsável pelo seu desapparecimento ou deterioração culpável;

$\S 12^{\circ}$. Enviar á secretaria da instrucção, no fim de cada mez e por intermédio do inspector escolar, os dados estatísticos da sua escola (MATO GROSSO, 1896, p. 133).

Mais uma vez fica explícito que o professor, além de exercer a função docente em sala de aula e ministrar os conteúdos programáticos de forma atrativa, ainda tinha que atender as exigências morais, realizando funções de caráter administrativo, devendo elaborar relatórios, cuidar do mobiliário e dos diversos materiais utilizados pelos alunos, dentre outras responsabilidades. Analisando as obrigações exigidas, compreende-se que o professor exercia 
funções muito além do ensino-aprendizagem desenvolvido me sala de aula, refletindo a nítida ausência de recursos humanos para realizar as demais atividades inerentes ao espaço escolar.

O professor primário ainda poderia sofrer diversas sanções de cunho administrativo, sendo as penas variáveis entre admoestação ou repreensão até a perda do cargo, caso não cumprisse, por exemplo, o horário de aula no período estabelecido no regimento (conforme anteriormente destacado, o professor tinha que cumprir rigorosamente os horários de início e término das aulas, e ainda, cumprir com a previsão de carga horária a ser trabalhada na rotina escolar - vide programa escolar). As penas administrativas deveriam atender à razoabilidade (gradação) e a proporcionalidade de acordo com a falta cometida pelo docente, reservando-se assim as penas mais graves para o caso de reincidência do professor na conduta anteriormente já sancionada.

De uma análise geral das sanções previstas no Regulamento de 1896, observa-se que a grande maioria tinha conotação moral. O professor desde a sua admissão deveria primar por uma conduta moral ilibada, exemplar e de respeito com os alunos, devendo dar bons exemplos, tendo em vista que o exercício da docência neste período era encarado como um verdadeiro sacerdócio.

A idoneidade exigida do professor era reflexo da seriedade atribuída ao exercício da profissão docente nos anos iniciais do século XX, e diante das exigências para ingresso (atestados e documentos que atestassem a idoneidade, e ainda, prova escrita e oral para averiguação do conhecimento acerca dos pontos sorteados), verifica-se que, muito embora as regras de conduta, os professores que seriam contratados teriam certa liberdade no exercício diário da profissão, vez que, os pontos do programa previsto (que serão apresentados adiante) eram apenas uma noção básica do conteúdo principal a ser ensinado aos alunos. Neste ponto, vejamos as considerações abaixo em destaque sobre a liberdade do professor em sala de aula:

\footnotetext{
Diante das disposições gerais atribuídas pela sociedade à escola, os professores dispõem de uma ampla liberdade de manobra: a escola não é o lugar da rotina e da coação e o professore não é o agente de uma didática que lhe seria imposta de fora. Mesmo se a corporação à qual pertente exerce uma pressão - quer se trate de visitantes de uma congregação, ou de inspetores de diversas ordens de ensino -, ele sempre tem a possibilidade de questionar a natureza de seu ensino (JULIA, 2001, p. 33).
}

Referida liberdade, conforme dito sofria algumas limitações, tais como: restrições nas palavras a serem utilizadas em sala de aula; conteúdo e outros. O professor da Primeira República deveria ser digno do exercício do "mister de professor", em nenhuma hipótese poderia fomentar a imoralidade ou conduta violadora dos bons costumes sociais. Muito embora 
o ideário acerca do "perfil docente", a realidade retratada em documentos oficiais do período revela que na prática, poucos docentes se enquadravam nas exigências para a profissão.

Antonio Paes de Barros (um dos presidentes do Estado de Mato Grosso do período), admitia em mensagens presidenciais destacadas nos estudos de Leite (1970), que o ramo da educação primária estava exigindo algumas reformas e apesar de reconhecer que as condições financeiras do Estado não comportavam despesas, ao mesmo tempo, destacava a ausência de pessoal habilitado para a regência das escolas primárias, acrescidos à falta de vocação de muitos profissionais do magistério.

O que se alçava por meio da mensagem do Presidente Pedro Leite Osório, mais uma vez citado por Leite (1970), demonstrava que as escolas públicas desse período, em geral eram regidas por professores mal preparados e sem a indispensável vocação para o magistério, longe de satisfazer as necessidades das crianças que frequentavam a escola. Certamente, outro resultado não seria alcançado, em virtude do pouco investimento conferido a grande maioria dos professores que atuavam na escola pública primária, considerando que o maior número de escolas eram as Isoladas nas zonas urbanas e rurais. Neste cenário, os professores apenas perpetuavam as experiências mal sucedidas do período do Império.

Em concordância, merece destaque os dados estatísticos apresentados nos estudos de Leite (1970) onde ressalta que no ano de 1899, a frequência contabilizada era de 1.808 (mil oitocentos e oito) alunos, sendo que 1.255 (mil duzentos e cinquenta e cinco) eram do sexo masculino e 553 (quinhentos e cinquenta e três) eram do sexo feminino. Neste ano, o Estado de Mato Grosso contava com 59 escolas públicas, sendo 15 para meninos, 15 para meninas e 29 Escolas Mistas. Comparados com os números levantados no ano anterior (1898) houve um acréscimo significativo de 227 alunos (ou seja, em 1898 a frequência era de apenas 1.581 - mil quinhentos e oitenta e um).

Porém, no ano de 1900 o Estado contava com 62 escolas, dos quais 57 eram elementares ou do $1^{\circ}$ Grau e 5 complementares, observa-se que mais de $90 \%$ (noventa por cento) eram escolas com professores de $1^{\circ}$ Grau que recebiam o valor de 1:000\$000 (Um milhão de réis), sendo que este valor somente era alçado com o recebimento de gratificação e ainda correspondia à remuneração anual do professor.

Leite (1970) continua destacando que no ano de 1909 funcionaram 70 (setenta) escolas e matricularam-se 2.678 (dois mil seiscentos e setenta e oito) alunos, sendo 1.562 (um mil quinhentos e sessenta e dois) meninos e 1.116 (um mil cento e dezesseis) meninas, não incluindo a matrícula de 22 escolas, cujos professores não remeteram os respectivos mapas, 
sendo que a referida conduta era habitual de muitos docentes, que em decorrência da distância, baixa remuneração e as demais funções administrativas que eram obrigados a realizar, dificultavam o envio de documentos para os fins de levantamento de dados estatísticos.

\section{Concurso Público para ingresso na CARreira de Magistério: analisando os DOCUMENTOS INSTITUCIONAIS (1909)}

Em decorrência da necessidade de cumprir com os ideários republicanos (ensino obrigatório, gratuito e com professores qualificados), o governante do Estado de Mato Grosso, após a criação de dezenas de escolas primárias, iniciou o processo seletivo para ingresso de professores na carreira docente.

Com base nos critérios previstos no Regulamento de 1896, a Administração pública, com base no princípio da impessoalidade ${ }^{2}$, almejava, sobretudo, contratar professores que não seriam apenas "indicados” por familiares ou funcionários do Estado, mas iriam ser efetivados no cargo público mediante prévia aprovação nos exames que lhe seriam aplicados, conforme os conhecimentos necessários e exigidos para o exercício da docência. Os concursos públicos eram realizados mediante prévia autorização do Presidente de Estado, e mediante a vacância de escolas existentes ou criadas que necessitavam de professor.

O artigo 201 do Regulamento de 1896, também apresentava a periodicidade de realização do concurso: no início de dezembro de cada ano, o diretor anunciaria o certame, devendo ser observado o prazo máximo de 90 (noventa) dias para o preenchimento das cadeiras vagas indicadas em edital.

Em atendimento ao previsto no dispositivo legal em apreço, o edital da Instrução Pública (juntado nos anexos da pesquisa) nos permite compreender que o Processo de Concurso Público para o Provimento Efetivo da Escola Mista Elementar do Coxipó do Ouro obedeceu à regularidade determinada na legislação.

É importante destacar que o Edital do concurso foi editado sob a égide do governo Pedro Celestino Correia da Costa, na ocasião, Presidente do Estado de Mato Grosso conhecido pelos

\footnotetext{
${ }^{2} \mathrm{O}$ princípio da impessoalidade foi inserido expressamente no texto normativo legal com a promulgação da Constituição Federal de 1988, onde, apresenta no seu artigo 37 diversos princípios que deverão ser observados pela administração pública, dentre eles, a impessoalidade, que reflete diretamente na obrigatoriedade de realização de concurso público para os fins de contratação de pessoal para exercer as funções de responsabilidade do Estado. No período em estudo, tem-se que o princípio, muito embora não tivesse previsão expressa na lei, já estava inserido, implicitamente, na concepção do novo estado de direito que surgiu com a proclamação da República no Brasil.
} 
atos realizados no que tange à expansão da Instrução Pública Primária em território matogrossense.

Neste sentido não seria diferente reconhecer que a abertura de mais de 46 (quarenta e seis) vagas tinha a intenção de atender as necessidades da população do Estado que na época contava com uma extensão territorial de aproximadamente 1 (um) milhão e meio de quilômetros quadrados e ainda abrangia os territórios de Rondônia e Mato Grosso do Sul. ${ }^{3}$

Com a abertura do Concurso, os candidatos deveriam se inscrever na sede da Secretaria da Instrução Pública, e mediante requerimento pessoal, instruído com os documentos já mencionados para que mediante apreciação da regularidade dos documentos ocorresse a efetiva publicação dos inscritos no Edital.

A documentação exigida no Artigo 203 do Regulamento de 1896, deveria ser apresentada mediante requerimento pessoal subscrito pelo próprio candidato e direcionado ao diretor geral, exigência esta que, conforme fontes inventariadas no arquivo público, foram regularmente cumpridas pela candidata Esmeraldina da Silva Paes, conforme aponta a Figura 3.

Figura 3 - Requerimento de inscrição Esmeraldina da Silva Paes, 1909

\begin{tabular}{|c|c|c|}
\hline 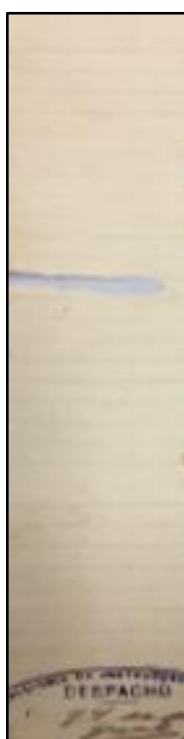 & 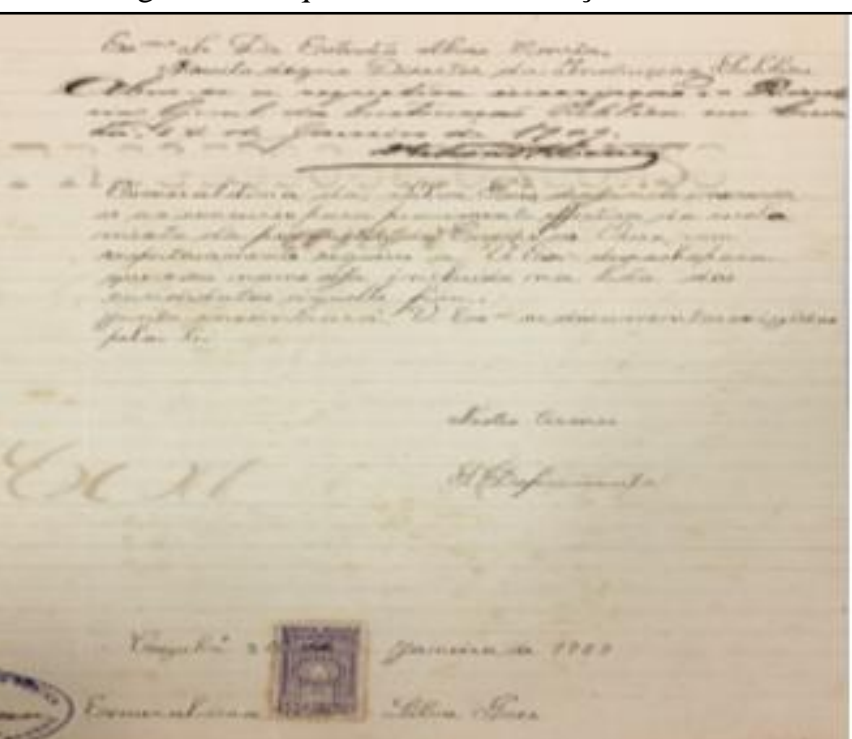 & $\begin{array}{l}\text { Exmo. Sr Dr Estevão Alves Corrêa, } \\
\text { Muito digno Director da Instrucção } \\
\text { Publica. } \\
\text { Abra-se a respectiva inscripção. } \\
\text { Directoria Geral da Instrucção Publica } \\
\text { em Cuiabá, } 27 \text { de janeiro de } 1909 \text {. } \\
\text { Esmeraldina da Silva Paes, desejando } \\
\text { inscriverse ao curso para provimento } \\
\text { effectivo da escola mixta da povoação } \\
\text { do Coxipó do Ouro vem } \\
\text { respectivamente requerer a V. Exa } \\
\text { despacho para que seu nome seja } \\
\text { incluido na lista das candidatas aquele } \\
\text { fim. Junto encontrará V. Exa as } \\
\text { documentas exigidas pela lei. } \\
\text { Nestes Termos. Pede Deferimento. } \\
\text { Cuyabá } 26 \text { de janeiro de } 1909 \text {. } \\
\text { Esmeraldina da Silva Paes. }\end{array}$ \\
\hline
\end{tabular}

Fonte: Arquivo Público de Mato Grosso.

\footnotetext{
${ }^{3} \mathrm{O}$ atual Estado de Mato Grosso passou por dois processos de divisão: o primeiro ocorrido em 1943, quando deu origem ao território de Guaporé, atual Estado de Rondônia, e por fim, adveio a Lei Complementar editada em 11 de outubro de 1977 pelo governo Ernesto Geisel dando origem ao Estado de Mato Grosso do Sul. (Adaptado do site de notícias www.g1.com.br).
} 
Após o requerimento, o responsável pelo concurso público procedeu o deferimento do pedido de inscrição, se manifestando sobre a inscrição realizada pela candidata Esmeraldina da Silva Paes, destacada na Figura 4.

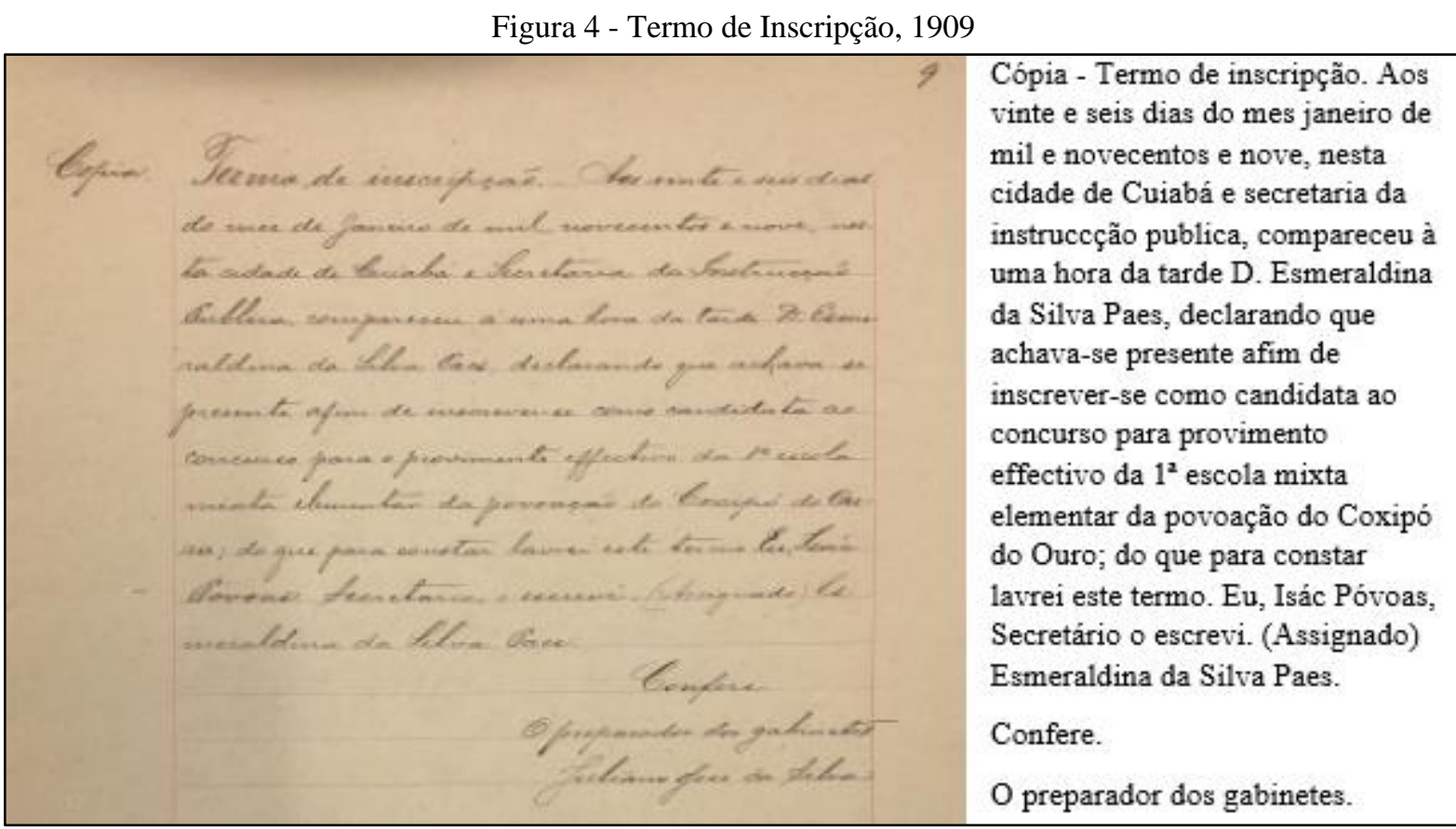

Fonte: Arquivo Público de Mato Grosso.

O conteúdo programático referente aos tópicos do exame foi apresentado no Artigo 211 do referido Regulamento:

Art. 211. Os concursos para o provimento effectivo das escolas primarias versarão sobre as matérias do curso elementar ou do complementar, conforme pertencer a um ou outro a cadeira que se tratar de prover (MATO GROSSO, 1896, p.127).

As matérias objeto do exame seriam os conteúdos provenientes do curso elementar ou de $1^{\circ} \mathrm{Grau}$, tendo em vista que, somente duas vagas foram ofertadas no Edital para o exercício da docência em curso complementar ou de $2^{\circ}$ Grau.

O Concurso deveria ser realizado em duas fases: prova escrita e prova oral, sendo que em ambos os casos, a banca examinadora designada pelo Presidente do Estado de Mato Grosso deveria sortear o conteúdo para cada candidato, com base nos 20 (vinte) pontos previamente formulados para o exame. As provas escritas poderiam ser idênticas a todos os candidatos e deveriam ser aplicadas no prazo máximo de duas horas, devendo ainda, com objetivo de identificação pessoal, serem datadas e assinadas pelo candidato.

Em relação ao conteúdo é necessário reiterar a prescrição oficial inerente ao ensino elementar ou de $1^{\circ} \mathrm{Grau}$, tendo em vista que no exame em evidência consta a informação na 
capa da prova que a candidata Esmeraldina realizava a prova para os fins de preenchimento da cadeira docente disponibilizada na "Escola Mixta do Cóxipo do Ouro", conforme a Figura 5.

Figura 5 - Concurso Escola Mixta Elementar Coxipó do Ouro, 1909

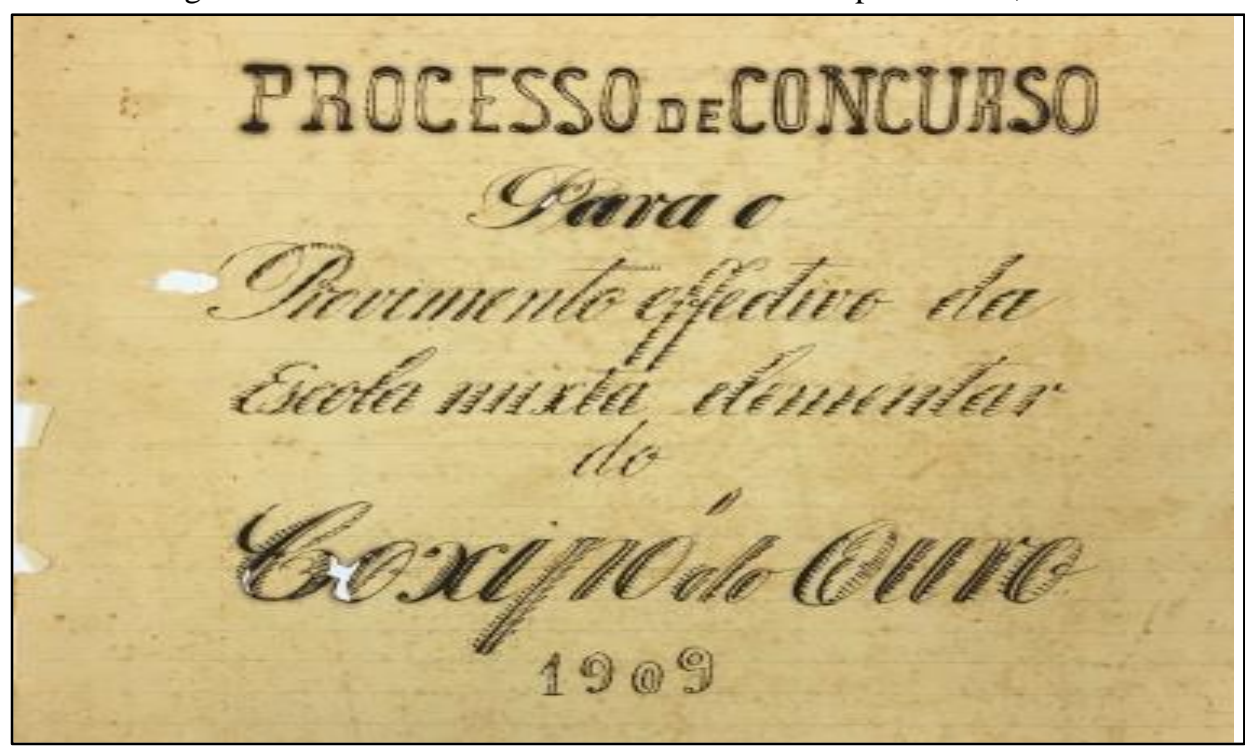

Fonte: Arquivo Público de Mato Grosso.

Conforme consta no edital e devidamente explicitada na Figura 5, a única vaga disponível para o Povoado do Coxipó do Ouro era para atuar na $1^{\text {a }}$ Escola Elementar Mista (ou seja, para ambos os sexos), e assim, depreende-se que se tratava de uma única escola para o público de matrícula e frequência obrigatória, repita-se, os infantes de 7 (sete) a 10 (dez) anos de idade. Por se tratar de cadeira na carreira de magistério para o ensino elementar, as matérias que a candidata Esmeraldina deveria ter conhecimento, eram as mesmas que deveriam ser trabalhadas com os alunos em sala de aula, conforme já apresentado no Artigo 10 do Regulamento.

O artigo 213 explicita que os conteúdos eram sorteados no dia da realização do exame:

Art. 213. As provas do concurso serão escripta e oral, e versarão ambas sobre o assumpto do ponto sorteado.

$\S 1^{\circ}$. A prova escripta será comum para todos os candidatos, e feita no praso máximo de duas horas; devendo ser datada e assignada pelo respectivo concurrente (MATO GROSSO, DECRETO n 152,1896$)$.

Depreende-se que a previsão do conteúdo a ser avaliado seria sorteado somente no dia da prova, cabendo aos candidatos ter conhecimento de todos os pontos a serem cobrados. Os Rituais do dia da prova também estavam previstos no Regulamento de 1896. A banca examinadora designada para os fins de realização do concurso de provimento das cadeiras de magistério, conforme previsão do artigo 209 deveria ser constituída por uma comissão a ser 
presidida pelo Diretor geral da Instrução Pública Primária e composta por dois examinadores nomeados pelo presidente do Estado de Mato Grosso.

No que se refere as avaliações, França (2016. p.124), aponta os estudos acerca dos exames e avaliações desenvolvidos por Ralph Tyler (educador americano que se dedicou ao estudo de métodos de avaliação mais eficientes) nos anos de 1930, que, embora tivesse surgido o termo "avaliação de aprendizagem" e esse autor demonstrasse a relação entre "instrumentos de avaliação" e "objetivos" na prática, permaneceram as provas (sabatinas) e os exames nos moldes tradicionais.

A mesma autora ainda menciona os estudos de Valente (2006) desenvolvidos no trabalho "dos exames para as provas e das provas para os exames", onde referido estudioso menciona que o professor de matemática deveria fazer com que seus alunos fixassem os pontos. Aos alunos, cabia a memorização e "com a lista deles, o candidato preparava-se para as provas escritas e orais".

Valente (2006) ainda menciona que exames, com provas escritas e orais constituíam o modo de avaliar alunos nos diferentes ensinos escolares, com bancas formadas por professores que priorizavam a justiça, o rigor e a imparcialidade e por isso, muitas vezes, eram estranhos aos estabelecimentos de ensino. Deste modo, observamos que o Edital do Concurso Público do ano de 1909 avaliava os candidatos do mesmo modo que os professores aprovados deveriam avaliar seus alunos em sala de aula.

Os examinadores do concurso, por sua vez, conforme disposição do artigo 210, deveriam ser professores públicos, ou seja, privilegiava-se quem já estava no exercício da carreira docente, sendo que na falta de professores em exercício, poderiam ser designados terceiros, desde que demonstrassem conhecimentos (notório saber), e fossem igualmente imparciais e idôneos.

Todos os atos do exame (prova escrita e prova oral) deveriam ser registrados em Ata própria de exame e, ao final, assinada por todos os componentes da banca avaliativa e pelos candidatos. Fato este que no documento inventariado denominado "Acta dos exames prestados pelas Senhoras D. Esmeraldina da Silva Paes e Eucharis Marques de Arruda, para o provimento effectivo das escolas mixtas das povoações do Coxipó do Ouro e da Passagem da Conceição", sendo que o exame foi realizado no dia 11 de fevereiro de 1909 na sala do edifício onde funcionava o "Lyceu Cuiabano".

A Banca examinadora era formada por três homens e apenas uma mulher, a D. Albina Valladares, conforme consta da ata dos exames, foi designada para apenas e tão somente, para 
avaliar as prendas domésticas das candidatas (até porque, referido feitio compõe o quadro de disciplinas a serem ensinadas para as meninas). Competia à Comissão examinadora previamente designada na véspera do exame, organizar 20 pontos (conteúdos), conforme o artigo $212, \S$ único, que deveriam ser sorteados entre os candidatos, não podendo ter repetição de pontos para os candidatos subsequentes, e assim, visava garantir o "elemento surpresa" das avaliações.

Ao analisarmos as fontes até então delineadas, fica evidenciada a obediência ao ritual dos procedimentos adotados no concurso público e que o objetivo do certame era conferir imparcialidade e confiabilidade, que, ao final, resultariam no Provimento efetivo das cadeiras de magistério.

\section{CONSIDERAÇÕES FINAIS}

A pesquisa explora diversos documentos que foram produzidos durante os primeiros anos da República Federativa do Brasil, especificamente no Estado de Mato Grosso, conhecido à época pela sua vasta extensão territorial.

O Regulamento da Instrução Pública editado no longínquo ano de 1896 revela diversos fatores esperados no futuro professor dos primeiros anos de escolarização do século passado: seriedade, competência para desenvolver as aulas, retenção dos alunos (tanto que a remuneração mensal poderia sofrer reduções ou até mesmo ser extinta), e, sobretudo, ter todos os requisitos legais preenchidos no momento da inscrição no concurso público.

Devemos ainda considerar que a sociedade nutria expectativas sobre o candidato ao ingresso na carreira docente, visto que, no período a obrigatoriedade do Estado era de promover a educação pública e gratuita, em decorrência dos novos ideários republicanos.

Conclui-se, pela análise dos documentos inventariados e analisados que todos os regramentos previstos no certame do ano de 1909 foram obedecidos e que os candidatos possuíam os conhecimentos necessários para exercer a tão honrosa profissão docente.

Merece destacar que a cultura escolar dos tempos de outrora contribui para o avanço da educação atual, especialmente, demonstra aos profissionais da educação as honrarias de tão nobre profissão.

\section{REFERÊNCIAS}

ALMEIDA, Laura Isabel Marques Vasconcelos de. Ensino de matemática nas séries iniciais no estado de Mato Grosso (1920-1980): uma análise das transformações da cultura escolar. 2010. 230 f. Tese (Doutorado em Educação). Pontifícia Universidade Católica do Paraná, Curitiba, 2010. 
CERTEAU, Michel de. A escrita da história. Rio de Janeiro, RJ: Forense Universitária, 1982.

CHERVEL, André. História das disciplinas escolares: reflexões sobre um campo de pesquisa. Porto Alegre, Pannonica, Teoria e Educação, 1990, p. 177-229.

FRANÇA, Iara da Silva. Formação matemática dos professores primários nos tempos da primeira república. Curitiba/PR. Editora: Appris, 2016.

JULIA. Dominique. A cultura escolar como objeto histórico. Revista Brasileira de História da Educação. Campinas, n.1, jan/jun.2001, p.9-43. Disponível em https://edisciplinas.usp.br/pluginfile.php/4250681/mod_resource/content/1/273-846-1-PB.pdf. Acesso em: 12 de set de 2018.

LEITE, Gervásio. Um século de instrução pública (História do Ensino Primário em Mato Grosso). Goiânia/GO: Ed. Rio Bonito, 1970.

MATO GROSSO. Decreto Lei no 152 de 16 de abril de 1896. Instituto Memória da Assembléia Legislativa do Estado do Mato Grosso. Disponível em https://www.al.mt.gov.br/institucional/instituto-memoria/. Acesso em maio de 2018.

MATO GROSSO. Regulamento da Instrução Pública, 1896. Instituto Memória da Assembléia Lesgislativa do Estado de Mato Grosso. Disponível em https://www.al.mt.gov.br/institucional/instituto-memoria/. Acesso em agosto de 2018.

VALENTE, Wagner Rodrigues. Dos exames para as provas e das provas para os exames: contribuição à história da avaliação escolar em matemática. IV Congresso Brasileiro de História da Educação, 2006. Disponível em http://www.sbhe.org.br/novo/congressos/cbhe4/individuaiscoautorais/eixo03/Wagner\%20Rod rigues\%20Valente\%20-\%20Texto.pdf. Acesso em Julho de 2018.

Recebido em: 24 de agosto de 2020. Aprovado em: 14 de dezembro de 2020. 